\title{
TECNOLOGIAS EDUCACIONAIS: Estratégias de formação de professores para uso de TIC em uma escola de Palmas - TO
}

EDUCATIONAL TECHNOLOGIES: Teacher training strategies for the use of ICT in a Desafios school in Palmas - TO

TECNOLOGÍAS EDUCATIVAS: Estrategias de capacitación docente para el uso de las

TIC en una escuela en Palmas - TO

\section{Raimundo Ferreira Rodrigues ${ }^{1}$; Darlene Teixeira Castro ${ }^{2}$}

${ }^{1}$ Mestre em Gestão de Políticas Públicas (2020), Graduado em Pedagogia (2005) e Comunicação Social: Jornalismo (2016) pela UFT. Professor da Rede Pública do Municipio de Palmas - TO. https://orcid.org/0000-0002-4279-6479. GESPOL UFT. Avenida NS 15, ALCNO 14 - Prédio do PPGDR, Campus Palmas. - Palmas - TO. Brasil. CEP: 77001-090.

2 Doutora em Comunicação e Culturas Contemporâneas pela UFBA (2012), Mestrado em Ciência da Informação pela PUC de Campinas (2005), Graduada em Letras (2001) e Jornalismo (2008) pelo Centro Universitário Luterano de Palmas. https://orcid.org/0000-0003-1867-3804. Unitins. Quadra 108 Sul, Alameda 11, 4 - Palmas - TO. Brasil. CEP: $77020-122$

Artigo recebido em 04/03/2020 aprovado em 25/08/2020 publicado em 31/10/2020.

\section{RESUMO}

A pesquisa trata sobre Tecnologias educacionais: estratégias de formação de professores para uso de TIC em uma escola de Palmas - TO. O problema averígua quais as contribuições das estratégias educativas de uso das TIC para o aprimoramento dos docentes da escola campo. Objetiva conhecer as contribuições das estratégias educativas de uso das TIC para formação dos docentes da instituição pesquisada. Utilizou-se a metodologia da pesquisa-ação, a partir estratégias educativas desenvolvidas na escola. Os resultados apontam que o professor tenta construir uma identidade docente coerente com a sociedade do conhecimento e da informação, mas se vê desprovido de apoio, com formação ínfima e descontinuada, sem valor em carga horária para a carreira, por não ter tempo para estudos ou poder custear continuidade na formação. Há necessidade de investimento em políticas públicas para a formação realmente continuada dos professores visto que perpassam por reveses, desafios constantes e se desdobram em busca de materiais e métodos favoráveis à sua atuação. As ações desenvolvidas serviram para capacitar os docentes, otimizar suas aulas com tecnologias pessoais e as que a escola dispõe, superar parte de suas dificuldades e fez com que se dispusessem a continuar buscando melhorias para a carreira e processo de ensino-aprendizagem.

Palavras-chave: Tecnologias. Formação continuada. Estratégias educativas.

\section{ABSTRACT}

The research deals with Educational Technologies: teacher training strategies for the use of ICT in a school in Palmas - TO. The problem finds out what are the contributions of educational strategies for the use of ICT for the improvement of teachers in the rural school. It aims to know the contributions of educational strategies for the use of ICT for the training of teachers in the researched institution. The action research methodology was used, based on educational strategies developed at school. The results show that the teacher tries to build a teaching identity that 
is coherent with the knowledge and information society, but finds himself lacking support, with minimal and discontinued training, with no workload for his career, because he does not have time for studies or be able to afford continuity in training. There is a need for investment in public policies for the real training of teachers, as they go through setbacks, constant challenges and unfold in search of materials and methods favorable to their performance. The actions developed served to train teachers, optimize their classes with personal technologies and those that the school has, overcome part of their difficulties and made them willing to continue seeking improvements for their careers and the teaching-learning process.

Keywords: Technologies. Ongoing training. Educational strategies.

\section{RESUMEN}

La investigación aborda las Tecnologías Educativas: estrategias de capacitación docente para el uso de las TIC en una escuela en Palmas - TO. El problema descubre cuáles son las contribuciones de las estrategias educativas para el uso de las TIC para la mejora de los docentes en la escuela rural. Su objetivo es conocer las contribuciones de las estrategias educativas para el uso de las TIC para la formación de docentes en la institución investigada. Se utilizó la metodología de investigación de acción, basada en estrategias educativas desarrolladas en la escuela. Los resultados muestran que el maestro intenta construir una identidad docente que sea coherente con la sociedad del conocimiento y la información, pero se encuentra sin apoyo, con una formación mínima e interrumpida, sin carga de trabajo para su carrera, ya que no tiene tiempo para estudiar o ser capaz de permitirse la continuidad en la capacitación. Es necesario invertir en políticas públicas para la formación realmente continua de los docentes, a medida que atraviesan retrocesos, desafíos constantes y se desarrollan en busca de materiales y métodos favorables para su desempeño. Las acciones desarrolladas sirvieron para capacitar a los docentes, optimizar sus clases con tecnologías personales y las que tiene la escuela, superar parte de sus dificultades y los hicieron dispuestos a continuar buscando mejoras para sus carreras y el proceso de enseñanza-aprendizaje.

Palabras clave: Tecnologías. Entrenamiento continuo. Estrategias educativas.

\section{INTRODUÇÃO}

A pesquisa trata sobre as tecnologias educacionais, especificamente em referência as estratégias de formação de professores para uso de TIC em uma escola de Palmas - TO. O trabalho procura fazer uma contribuição na área de educação, especificamente com a tessitura da ligação entre a utilização de tecnologias no cotidiano escolar com a formação docente em serviço. Sua construção ocorreu por meio de ações desenvolvidas durante o ano letivo de dois mil e dezenove, com a participação dos profissionais que compõem a instituição, visto que almejam melhorias na formação, pois historicamente há percalços que impedem a efetivação de formação em serviço coerente com o que é necessário para que os profissionais consigam a carga horária necessária para progressão vertical e horizontal exigida pela Rede de Ensino e para a melhoria salarial.

Outro entrave emergente, consiste em conseguir adequar a escola à contemporaneidade, 
tendo em vista que os recursos financeiros e tecnológicos disponibilizados são sempre poucos ou reduzidos, insuficientes para atender as demandas da comunidade escolar. Sobre este aspecto, a história tem mostrado que a escola não está totalmente preparada para os rumos do mundo contemporâneo. Alguns aspectos educativos foram e são deixados de lado. Neste sentido, como construir uma identidade docente sólida e coerente com a sociedade do conhecimento e da informação (sem apoio da instituição mantenedora da educação pública)? Como participar de formação que sirva para o plano de carreira (já que as instituições não oferecem, ou oferecem de forma descontinuada, sem valor em carga horária para a carreira, ou mesmo diante do custo de vida incoerente com os salários dos profissionais, não permitindo custear continuidade na formação)? Ou diante do que a comunidade espera de atendimento e principalmente o que o professor espera e quer oferecer para seus alunos e se vê de mãos atadas?

Há que se questionar sobre investimento em políticas públicas, para a qualidade da educação, pois a escola, principalmente a de tempo integral, passa por reveses e desafios constantes para atender seus usuários. Apoiar os profissionais da escola e manter uma qualidade, resumindo seu papel em manter os alunos na escola em tempo integral e pouco conseguindo fazer com que a educação seja oferecida integralmente.

A escola tem buscado se tornar um ambiente diferenciado por meio de seus métodos de ensinar e de aprender. Entretanto, fez-se necessário averiguar quais os percalços que desafiam os docentes e demais profissionais da escola a buscar materiais e métodos que sejam favoráveis à sua atuação no cotidiano escolar. A priori, no que se refere a formação e a uso de recursos tecnológicos para uso individual e coletivo, apresentam carência, tanto de quantitativo de equipamentos, quanto de capacitação relacionada ao saber utilizá-los. Visto que estes são reveses e entraves que assolam a maioria das escolas públicas, sendo esta, a realidade também da escola pesquisada.

A pesquisa desenvolvida na escola campo emergiu da necessidade apresentada pelos profissionais da instituição perante a falta de políticas públicas voltadas para formação continuada em serviço, direcionada para o ensino-aprendizagem que contemplasse a utilização de TIC. Isto vinha acarretando dificuldades no processo de gestão, que não dispõe de recursos financeiros, equipamentos suficientes, nem de profissionais com qualificação específica na área.

Os profissionais da escola necessitavam ter acesso as TIC e aprender a manusear os equipamentos tecnológicos para agregar mais este valor a seu currículo, refletindo na sua identidade docente. A continuidade na busca por novas metodologias e recursos inovadores apropriados para o processo de ensinar e de aprender na sociedade contemporânea requer do profissional mais entusiasmo, curiosidade e vontade de mudar a própria realidade e a dos seus alunos. Além disso, precisava de apoio da gestão da escola, que por sua vez, se ampara nas políticas públicas educacionais, pouco efetivas, descontinuadas ou inexistentes na Rede Municipal, mas que com a aplicação da pesquisa-ação, conseguiu ampliar as perspectivas do grupo em buscar novas possibilidade para a carreira dos docentes.

As políticas públicas do município de Palmas, voltadas para a formação dos profissionais da educação, têm se apresentado pouco evidentes, descontinuadas e as que são oferecidas são pouco atrativas devido às curtas cargas horárias, insuficientes para o aprender a fazer e para progressão na carreira. As poucas tentativas de se estabelecer educação continuada no município de Palmas, foram adiadas, fragmentadas, frustradas ou canceladas. Diante do exposto, Gentili (1996), argumenta que as políticas 
públicas e os paradigmas gerenciais evoluíram. E para suprir as demandas, houve o entendimento de que há que se buscar soluções para o gerenciamento e a qualidade educacional mediante o estabelecimento de parcerias com os que fazem a educação acontecer no cotidiano da escola.

O desafio emergente consiste na necessidade de a comunidade escolar tornar-se agente e sujeito no processo educacional (FERREIRA, 2008). A superação destes desafios, vem ocorrendo por meio de esforços individuais e em conjunto entre os profissionais da escola para que a formação continuada e o processo educativo na instituição sejam realizados de forma eficaz. Os esforços incluem a utilização de estratégias educativas com uso de tecnologias e a construção da identidade do profissional docente em serviço. A estratégia principal foi buscar parcerias com instituições que atuam com capacitação profissional para oferecer aos professores da instituição para que possam participar de cursos gratuitos, aprender a usar o que a escola tem de tecnologias e usar suas TIC pessoais, já que a escola não as possui.

A necessidade de busca por melhorias na formação dos professores é contínua e precisa ser oferecida pelas instituições mantenedoras da educação para todos os profissionais que atuam na escola pública, pois a qualidade na educação e melhoria em seus índices, é do interesse dos governos. Há a necessidade do estabelecimento de parcerias efetivas, responsáveis e contínuas.

A busca por formação pelos profissionais da escola ocorreu de forma coletiva, com a ajuda da gestão, de alguns parceiros e principalmente por cada profissional da instituição, fazendo parte da pesquisaação. Juntos, formularam estratégias e práticas educativas, a fim de proporcionar momentos de mediação de conhecimentos, partilha de saberes, troca de experiencias com uso de ferramentas tecnológicas educativas, que auxiliaram na construção da identidade docente e fortaleceram os processos de ensinar e de aprender na instituição campo. $\mathrm{O}$ uso destas TIC no contexto educacional ofereceu possibilidades de facilitação do trabalho na instituição, aliados com metodologias adequadas, foram atrativos diferenciados para utilização em sala de aula no fazer pedagógico diário.

Atuar com equipamentos tecnológicos, programas, aplicativos e redes, instigaram os envolvidos no processo de ensino-aprendizagem a vivenciarem processos estratégicos de inovação, tanto nos modos de ensinar e aprender, quanto na maneira de gerir a escola. Agregaram novos conhecimentos, estímulos voltados para a interatividade, multimidialidade, entre outras características que habilitaram os profissionais da educação a agirem na melhoria da carreira. Reconheceram que precisavam estabelecer continuidade em sua formação para se manterem atualizados, galgar novos níveis na escolaridade e no plano de carreira.

Diante dos reveses percebidos na instituição, os objetivos primordiais da pesquisa foram conhecer quais as contribuições das estratégias educativas de uso das TIC e o profissionalismo docente, desenvolvidos para o aprimoramento da formação continuada dos profissionais da escola. Em conjunto com o grupo gestor e com os docentes, buscaram meios para fortalecer a escola no enfrentamento frente aos desafios, e juntos desenvolver suas potencialidades. Imersos neste fazer educacional diário, engajados e afinados com o processo de gestão, foi possível estabelecer as prioridades e elencar as estratégias a serem desenvolvidas. As estratégias elencadas e utilizadas foram desenvolvidas por meio de oficinas, cursos de capacitação com carga horária adequada para o aproveitamento no plano de carreira.

Para atingir os objetivos propostos e responder a problemática, foi utilizada a pesquisa-ação (THIOLLENT, 1997), análise e descrição dos dados e 
das literaturas que tratam sobre o tema em questão que busca contribuir com a formação do professor e com o processo de ensino-aprendizagem na escola, principalmente no que se refere a utilização de tecnologias no contexto educacional por meio de ações que se apresentaram satisfatórias ao processo de ensino-aprendizagem. Outro aspecto relevante a se destacar é que os membros da instituição demonstraram interesse em resolver o problema e atuar juntos para minimizar suas dificuldades.

Esta pesquisa apresenta relevante importância acadêmica diante dos dados que não se esgotam em si. Eles estão disponíveis para continuidade nas pesquisas por quantos se interessem pelas informações disponíveis que demonstram os fazeres pedagógicos por meio de ações que evidenciam as tentativas de busca por melhorias no processo educativo na escola, no repensar a formação docente por meio de parcerias e pela ação coletiva. As ações desenvolvidas apresentam importância social e de formação dos profissionais, ao mesmo tempo em que proporcionam apoio a resolução de problemas da gestão que refletirão na qualidade dos serviços prestados à sociedade em geral.

\section{MATERIAIS E MÉTODOS}

Foi utilizada como metodologia a pesquisaação. Esta pesquisa contempla as ações de um grupo de profissionais e teóricos, que planejam, atuam e avaliam os resultados das ações desenvolvidas e monitoradas a partir de atividades. As ações foram executadas em um processo, repetidamente, por meio de uma espiral de passos até que os resultados satisfatórios fossem alcançados (THIOLLENT, 1997). Com perspectiva similar, Lewin (1946) enfatiza que a pesquisa-ação visa investigar e intervir favoravelmente frente ao equacionamento de determinado problema, ao longo do seu desenvolvimento, e, como resultado desse processo, produzir novos conhecimentos. As investigações demandam intervenções que conduzem à novas investigações, conforme espiral cíclico.

Nesta perspectiva, Thiollent (2011) e Lewin (1946) afirmam que o surgimento da pesquisa-ação é associado a situações de insatisfação com paradigmas, métodos de pesquisa clássicos e à necessidade de se promover maior articulação entre a teoria e a prática na mediação de conhecimento. Possibilita envolvimento direto entre os grupos sociais na compreensão e busca de soluções para seus problemas eminentes. Neste mesmo direcionamento, Adelman e Kurt (1993) discorrem que a pesquisa-ação, sustentada pela comunicação e cooperação entre pares, fortalece as relações sociais de grupos minoritários.

Ainda conforme descrição de Thiollent (1997), o processo de pesquisa-ação começou o seu ciclo com a identificação de um problema no seu contexto particular. Frequentemente, do facilitador externo foi solicitada a capacidade de "quebrar o gelo" através de dinâmicas de grupo de forma que os participantes pudessem interagir sem as amarras que tradicionalmente o ambiente e o convívio do cotidiano impõem.

Depois de identificar o problema dentro do contexto, os envolvidos na pesquisa-ação trabalharam para colecionar os dados pertinentes. As fontes de dados incluíram entrevistas, observação, análises do desenvolvimento das ações e informações consideradas relevantes. Colecionando dados sobre os problemas da organização, foi identificada a necessidade de mudança e a direção que esta mudança deveria tomar. Seguindo a diretriz de envolvimento, todos participaram na fase de coleta de dados.

Após coletar os dados, os participantes ajudaram a analisar e então geraram possíveis soluções aos problemas identificados. Além disso, o grupo buscou dar significado aos dados apresentando à comunidade para que pudessem agir com intervenções 
por meio de ações mais estruturadas para criar mudanças dentro do sistema. Os participantes das ações continuaram movendo por este ciclo até se esgotar os problemas que foram identificados inicialmente (GOLDSTEIN, 1992; THIOLLENT, 1997; JOE, 1998; LINDA; KAREN, 1999; HOLANDA; RICCIO, 2001).

Conforme pontuações de Le Boterf (1984), a pesquisa-ação insere o pesquisador como um membro do grupo observado, e dessa forma, compartilham as experiências de vida para melhor compreender seus hábitos e convenções sociais. Concebe também a possibilidade de emancipação das pessoas ou das comunidades que a realizam sendo possível "auxiliar os envolvidos a identificar por si mesmos os seus problemas, a realizar a análise crítica destes e a buscar as soluções adequadas" (LE BOTERF, 1984, p. 52). A seleção dos problemas estudados, emergiram dos próprios envolvidos, que os discutiram em conjunto.

Segundo Brandão e Steck (2006), um repertório múltiplo e diferenciado de experiências de criação coletiva de conhecimentos destinados a superar a oposição entre sujeito e objeto no interior de processos que geram saberes e na sequência de ações que aspiram gerar transformações, adapta-se a diferentes situações concretas. Conforme os objetivos perseguidos, os recursos disponíveis e o contexto sociopolítico em que se desenvolve, tendo suas origens na ação educativa, efetivam "uma pesquisa que é também uma pedagogia que entrelaça atores-autores e que é um aprendizado no qual, mesmo quando haja diferenças essenciais de saberes, todos aprendem uns com os outros e através dos outros" (BRANDÃO e STRECK, 2006, p. 13).

\footnotetext{
1 Para iniciar a pesquisa-ação, foram apresentados à SEMED e para a direção da escola campo, ofícios, solicitações de autorização de pesquisa, questionários de participação, projeto de pesquisa, ementas do curso de capacitação a ser desenvolvido e termos de participação. Estes documentos e tramites foram necessários mesmo
}

O método da pesquisa-ação por meio do "estudo-ação" atua como práxis perante os problemas que propõe uma postura de devolução do conhecimento aos grupos que deram origem a esse conhecimento. Isso exige que o pesquisador se envolva como agente, no processo que estuda, já que tomou uma decisão em favor de determinadas alternativas, aprendendo assim não apenas por meio da observação, mas do próprio trabalho com as pessoas com quem se identifica (FALS BORDA, 1980).

$\mathrm{O}$ objetivo metodológico fundamenta-se na pesquisa qualitativa que segundo Flick (2009a), direcionou explorar a subjetividade na constituição do conhecimento por meio da interação entre os sujeitos participantes e pesquisador no envolvimento construtivo da realidade social, como meio reflexivo do saber subjetivo, em que sua característica geral incide em se ocupar em estudar as experiências e interações desenvolvidas em seus contextos, de modo amplo, tanto no âmbito acadêmico quanto fora dele, preocupando-se com a qualidade e com a elevação do nível da pesquisa.

O procedimento metodológico para fundamentar a temática, foi desenvolvido por meio da análise de livros e artigos científicos referentes a este estudo, no intuito de filtrar os dados encontrados a respeito do tema em questão. Foi utilizada ainda a forma de análise crítica e interpretativa verificada nos textos científicos.

O local metodológico do estudo implica pesquisa-ação em uma escola de tempo integral adaptada do município de Palmas ${ }^{1}$ Tocantins, por ser o campo de atuação de estudo no curso identificado por ser o local de atuação profissional. As ações

sendo uma coleta simples de livre opinião. Diante da autorização da SEMED, da Gestão da escola e do consentimento livre e esclarecido de cada membro participante, a pesquisa-ação foi desenvolvida. Foi estabelecido pelos participantes, diante do termo de consentimento livre e esclarecido e pelos resultados de livre 
contemplaram atividades com vinte e sete professores. Não houve restrição no público de professores participantes, sendo aberto para todos participarem das oficinas intituladas "as tecnologias no cotidiano da escola", efetivadas na escola campo, com cinco (5) horas de duração. Participaram de um curso on-line "práticas de informática na educação", com duração de quarenta e cinco horas (45), oferecido por instituição parceira. A terceira oficina foi a de elaboração de projetos com duração de 5 horas. A ação seguinte foi o desenvolvida pelos professores por meio de atividades com uso de tecnologias em suas respectivas salas de aula, em dias alternados, com duração de vinte (20) horas, perfazendo um total de setenta e cinco (75) horas.

A pesquisa foi desenvolvida por meio de levantamento de dados em função das variáveis vinculadas ao tema para se definir uma atuação prática coletiva que respondessem quais as contribuições das estratégias educativas de uso das TIC para o aprimoramento dos docentes da Escola Municipal de Tempo Integral campo de pesquisa.

\section{RESULTADOS E DISCUSSÃO}

Tem sido um desafio para a comunidade escolar tornar-se agente e sujeito no processo educacional. Entretanto, existem esforços para que o processo educativo seja realizado de forma eficaz. Os esforços incluem a utilização de estratégias de formação para uso de tecnologias da informação e da comunicação (TIC) para construção da identidade do profissional docente em serviço, em função do desenvolvimento de sua ação educativa diária na

opinião relacionados a pesquisa que envolve a participação dos profissionais da escola, inclusive o próprio autor como autor e ator participante na pesquisa, além de incidir em ação voluntária entre ambos e com a efetivação de parceria entre os profissionais, a escola e uma instituição de ensino superior (privada) que ofertou gratuitamente os cursos de capacitação. Diante do exposto, com a assinatura do termo, escola. Ou mesmo diante de sua necessidade emergente de formação, suscetível a auto formação, mas que perpassa por frustrações por não conseguir atingir seus objetivos na formação e no plano de carreira conquistado a duras penas.

O estudo permitiu verificar frente as diferentes concepções de construção da profissionalização docente, que a identidade profissional do professor como intelectual transformador da sua realidade pela formação continuada e do seu fazer pedagógico embasado em práticas inovadoras com uso de recursos e estratégias da prática docente, fortalece sua carreira.

Casado, Siluk e Zampieri (2012), enfatizam que atualmente estamos vivenciando a era da informação, do conhecimento e apresentam tendências que indicam que a vida no século XXI será pautada pelo aprendizado contínuo, criatividade, inovação e pelo empreendedorismo envolvendo as diversas áreas de atuação e composição da sociedade.

$\mathrm{Na}$ escola, a promoção dos processos de inovação, se ampliam e encontram subsídios na utilização de TIC pelos docentes no cotidiano escolar. Neste sentido, os agentes de inovação e de conhecimento, dão conta de criar e pôr em prática projetos e ações minimizadoras das dificuldades, de promover o envolvimento e concretização da democracia no meio educacional. O processo de inovação vem sendo construído paulatinamente com respaldo das ações desenvolvidas e por meio de capacitação dos docentes que encontra na formação, subsídios para efetivação da educação, que aliada às tecnologias e atuando cada vez mais unidas a fim de

cada participante ficou ciente dos objetivos da pesquisa, que consistiu em conhecer as dificuldades de formação, desenvolver capacitação profissional com certificação pela faculdade parceira e o desenvolvimento coletivo e individual de estratégias educativas com uso de TIC no aprimoramento dos docentes da escola campo de pesquisa. 
diminuir as distâncias e flexibilizar a forma de ensinar e de aprender (AVILA, 2012).

Foi percebido que a construção da formação docente é desenvolvida como um fenômeno em constante transformação em busca de melhoraria como profissional. A identidade docente está intimamente ligada à formação, a profissionalização e passa por transformações em "função de circunstâncias efetivadas conforme a tradição de ser professor, com as exigências de mudanças elaboradas pela sociedade e que são depositadas no trabalho de cada sujeito educador" (BRZEZINSKI, 2002, p. 7).

Avila (2012) discorre que o professor é um ser único, entretecido pela trajetória pessoal e profissional. Ele se constrói nas relações que estabelece com os outros, com a história social que almeja. Este processo se efetiva na medida em que o professor amplia sua consciência sobre a própria prática docente e busca novas formas de fazer o seu trabalho. Este processo de formação, segundo Tardif e Lessard (2011), conduz ao reconhecimento de que a continuidade na formação e a trajetória docente, requer do profissional, atitude, ações transformadoras do fazer pedagógico diário, busca contínua por condições metodológicas, parceria e apoio para atingir os objetivos da educação.

É plausível que as instituições em que o profissional atua auxiliem seus docentes sendo fomentadoras permanentes da capacitação e do oferecimento de recursos didáticos e tecnológicos suficientes para manter estas formações, que aliados com a força de vontade e criatividade do educador, consegue destaque e estimula seus pares a aderir ao processo de busca e valorização dos saberes ${ }^{2}$ construídos e das práticas cotidianas.

\footnotetext{
${ }^{2}$ Refere-se a saberes de acordo com o que coloca Tardif (2002), como saberes mobilizados e empregados na prática cotidiana, saberes esses que dela se originam, de uma maneira ou de outra, e que servem para resolver os
}

As transformações recorrentes em nossa sociedade são constantes pela presença das TICs, que segundo Pretto (2017, p. 106) os currículos, a formação docente, os materiais educacionais, tudo está em questão, sendo evidenciado. E os docentes que estão mais próximos desta realidade são desprovidos de iniciativas de criação de estratégias para enfrentamento dos desafios identificados. O cenário atual nas escolas conduz a um paradigma de rara integração das TIC no ensino.

Mesmo com pouco ou nenhum recurso, ações educativas com uso de TIC são desenvolvidas na escola por profissionais dispostos a inovar no processo de ensinar e de aprender, visto que a sociedade contemporânea exige habilidades e recursos tecnológicos adequados para o êxito das ações. Os professores e gestores vivenciam desafios constantes e, muitas vezes, se sentem perdidos e despreparados. Enquanto algumas instituições conseguem adquirir novas TICs e os profissionais conseguem se adaptar aos processos digitais, outros perpassam transição penosa, sem formação e sem tecnologias adequadas (LAPA E PRETTO In. DIAS, MOREIRA, QUINTAS-MENDES (Org) 2019, p. 102).

São diversos os desafios que a escola enfrenta para diminuir as dificuldades de acesso às tecnologias (LEMOS; COSTA, 2007), visto que os professores que têm acesso e usam as TICs na escola "para se comunicar, produzir e socializar conhecimento e cultura, e os que não têm acesso, não compreendem o contexto tecnológico contemporâneo e não conseguem se articular para aprender, reivindicar, propor e provocar transformações na sociedade" (BONILLA, 2011, p. 179).

problemas dos professores em exercício e para dar sentido às situações de trabalho que lhes são próprias. 
Há ampla demanda de formação docente para uso das tecnologias. "Demanda uma formação que inclua, the possibilitar adentrar no universo da cibercultura e viabilizar que os professores possam ter acesso aos equipamentos para que possam soltar a sua imaginação, navegar na rede por este universo de imagens e informação" (CASTRO, 2017, p.112).

O intuito desta pesquisa-ação desenvolvida na escola incide sobre ações que contemplam o uso das tecnologias no cotidiano escolar, visto que os meios tecnológicos facilitam o trabalho na ação educativa, despertam o interesse dos alunos, provocam curiosidade, apresentam recursos diferenciados por meio de som, texto, imagem em movimento, explora as potencialidades que a internet proporciona, oferecendo diversos recursos e equipamentos tecnológicos, principalmente no que se refere a facilidade de pesquisa, interação, armazenamento e compartilhamento de informação, facilitando o processos de ensinar e de aprender.

Para elencar ações coletivas para serem desenvolvidas por meio da utilização de tecnologias no cotidiano da escola, foi necessário promover reuniões com os profissionais da escola para saber quais as suas dificuldades e problemas enfrentados para que juntos fosse possível compartilhar tanto as suas dificuldades, quanto suas potencialidades à serem trabalhadas durante a pesquisa, sabendo que todos os componentes buscam superar suas limitações por meio da formação e de ações coletivas desenvolvidas.

$\mathrm{O}$ instrumento de coleta de dados consiste em um questionário com questões objetivas e questões abertas. Foi estabelecido pelos participantes que primeiro preencheriam o termo de consentimento livre e esclarecido produzido para resguardar os membros da pesquisa-ação, assegurando a confidencialidade dos dados coletados e anonimato dos participantes, amparados pela Resolução 466/12, no artigo XIII.3, e Resolução 510, de 07 de abril de 2016 do Conselho
Nacional de Saúde, que reconhece as especificidades éticas das pesquisas nas Ciências Humanas e Sociais e de outras que se utilizam de metodologias próprias dessas áreas, dadas suas particularidades. Nesta perspectiva, em virtude da segurança dos dados e dos sujeitos da pesquisa, foi decidido e cada participante recebeu um pseudônimo seguindo o padrão das letras do alfabeto (PROFESSORA “A”, "B", “C” ... "Z").

Em dois momentos distintos, os profissionais da escola responderam aos questionários da pesquisa, sendo o primeiro questionário com intuito de verificar o panorama das experiências profissionais, prioridades, conceitos, perspectivas dos docentes, dificuldades, sobre alguns pontos relacionados a sua prática na sala de aula e as suas necessidades de formação para o processo de ensino-aprendizagem, relacionadas ao tema em questão e a partir dos resultados apresentados nos questionários, em conjunto com o grupo envolvido na pesquisa, foram elaboradas e desenvolvidas ações que possibilitaram minimizar as dificuldades e problemas enfrentados por estes profissionais. E em um segundo momento, após as ações desenvolvidas, foram identificadas e apontadas as contribuições das estratégias educativas desenvolvidas por meio do uso das TIC que se apresentaram satisfatórias para o aprimoramento dos docentes da Escola campo.

Foi estabelecido pelos envolvidos, que a participação na pesquisa incide em ação voluntária entre ambos e com a efetivação de parceria entre os profissionais, a escola, uma instituição de ensino superior (privada) e o pesquisador mestrando em Gestão de Políticas públicas (UFT), em função da efetivação da pesquisa supracitada. Diante do exposto, com a assinatura do termo, cada participante ficou ciente dos objetivos da pesquisa, que consiste em conhecer as dificuldades de formação, desenvolver capacitação profissional e estratégias educativas com 
uso de TIC no aprimoramento dos docentes da escola campo de pesquisa.

Os profissionais envolvidos receberam todas as informações necessárias para poder decidir conscientemente sobre a participação na pesquisa, podendo interrompê-la a qualquer momento. Os dados pessoais foram mantidos em sigilo e os resultados da pesquisa utilizados para alcançar os objetivos do trabalho, incluindo sua apresentação em encontros científicos e publicação em revistas especializadas.

A coleta de dados, capacitação, oficina e ações educativas com uso das TIC foram realizadas na própria escola no período de junho a outubro de dois mil e dezenove e contemplaram atividades com vinte e sete (27) professores. Não houve restrição no público de professores participantes, sendo aberto para todos os profissionais fazerem parte das oficinas intituladas "a utilização de tecnologias no cotidiano da escola", efetivadas na escola campo, com cinco (5) horas de duração. Participaram de um módulo on-line intitulado "práticas de informática na educação" com atividades de leitura, chat e avaliação objetiva, com duração de quarenta e cinco horas (45), oferecido por instituição de ensino superior parceira. A terceira oficina foi a de elaboração de projetos com duração de 5 horas. A ação seguinte foi desenvolvida por alguns professores por meio de atividades com uso de tecnologias em suas respectivas salas de aula, em dias alternados, com duração de vinte (20) horas, perfazendo um total de setenta e cinco (75) horas. Após a conclusão da pesquisa, as informações foram analisadas e disponibilizadas para a instituição.

Uma das estratégias foi a efetivação da capacitação presencial ministrada pelo proponente da pesquisa-ação, que teve sua efetivação por meio de oficinas de preparação, montagem e utilização de tecnologias no cotidiano escolar, desenvolvidas com vinte e sete professores e com carga horária de cinco (5) horas de duração. Em continuidade as ações, foi pertinente o desenvolvimento de oficina de projetos e troca de experiencias, em que os participantes apresentaram os métodos, técnicas e materiais para utilização nas aulas, com intuito de averiguar os possíveis efeitos positivos no processo educativo no cotidiano escolar.

O primeiro encontro da formação transcorreu na primeira semana de agosto do corrente ano, teve duração de cinco horas, foram apresentados alguns conceitos e histórico sobre as tecnologias, inovação tecnológica, sociedade da informação e do conhecimento e as tecnologias aplicadas na educação. Foi apresentado aos participantes a parte prática por meio de técnicas de montagem de equipamentos com treinamento com participação individual e coletiva, confecção de material didáticos necessários para utilização nas ações posteriores, desenvolvidas pelos professores em sala de aula e nos espaços da instituição, ambos com foco nas habilidades dos profissionais e voltadas para as disciplinas em que eles atuam e sentem maior dificuldade, principalmente no que se refere a utilização das tecnologias no dia a dia da escola.

De acordo com os resultados obtidos, foram identificadas as necessidades dos professores e elencados os principais conteúdos para serem apresentados e as principais TIC utilizadas no desenvolvimento da capacitação. O primeiro recurso apresentado consistiu no acesso e utilização de alguns recursos do Google, tais como o Google motor de busca, Classroom e Google drive. O acesso aos recursos do Google foi feito por meio dos celulares dos participantes.

Outra atividade consistiu no acesso ao Google Drive, cada professor conseguiu criar uma conta no gmail.com e visualizar o ambiente, tentaram fazer o upload de alguns arquivos em PDF, mas só alguns conseguiram. Mesmo assim, ficaram satisfeitos com a possibilidade de armazenamento de seus trabalhos e 
atividades escolares por meio deste serviço de disco virtual que oferece espaço para armazenamento gratuito dos arquivos na nuvem do Google e possui aplicativos para sincronização para Windows, Mac e Android, sendo possível utilizar o próprio celular que cada docente possui.

A próxima atividade foi a continuação das pesquisas no Google em busca de conteúdos e imagens pertinentes as disciplinas que cada professor leciona, com intuito de selecionar material para elaboração de atividades para aplicação em sala de aula. Os objetivos desta pesquisa foram de aprendizagem para formatação de conteúdos e imagens dispostas nas atividades, enfatizando que todos os conteúdos e imagens devem ser referenciados de acordo com as normas da ABNT, pois mesmo as imagens devem conter as devidas fontes ou créditos dos seus autores. Para esta atividade foi utilizado os celulares dos docentes, um notebook, Datashow, motor de busca Google, Adobe Reader, textos em PDF e o Paint para produção de atividades. Foi demonstrado como editar as imagens utilizando os programas citados, referenciar os autores, formatar e salvar em Word, PDF e armazenar no computador utilizado e em nuvem, facilitando a produção de atividades escolares com vistas aos cuidados com plágio de textos e de imagens. Pesquisar e salvar artigos do scielo e livros gratuitos disponíveis em domínio público.

A atividade seguinte, transcorreu com a utilização do Youtube, por meio de buscas por canais e vídeos educativos. Os professores fizeram buscas por vídeos, filmes e documentários, percebendo que com a utilização deste recurso podem diversificar suas aulas, proporcionando mudanças na maneira que expõem os conteúdos escolares.

\footnotetext{
3 Smart TV é uma expressão da tecnologia que significa "televisão inteligente", TV conectada ou TV Híbrida, porque é uma junção da televisão com a internet. Disponível
}

A escola possui algumas tecnologias que são utilizadas por parte dos professores. Entretanto, alguns docentes sempre solicitam algum colega para ajudálos a manusear. Com isso, foi selecionado um de cada recurso tecnológico disponível na escola para apresentar para todos o passo a passo de como montar e utilizar em suas aulas. Os primeiros recursos foram nomeados como Kit tecnológico, que consistiu na montagem com interligação do Datashow, notebook, caixas acústicas e microfone. A ênfase foi no Datashow, o qual foi utilizado para projeção de slides, vídeos e textos. Os professores que apresentavam mais dificuldades foram os primeiros a serem convidados para desmontar e montar novamente o equipamento. Alguns tiveram que montar mais de uma vez e todos conseguiram montar, selecionar conteúdos no computador e projetar as imagens em sala por meio do Datashow.

A próxima atividade foi desenvolvida por meio de demonstração de uso da Smart TV³. Foi utilizada uma Smart TV instalada na sala de aula, a qual os professores fizeram acesso ao Youtube e canais de filmes Netflix, por serem os meios mais interessantes escolhidos pelos professores, ficando para outra oportunidade o acesso aos demais programas disponíveis no aparelho tais como Twitter, AccuWeather, Facebook e Midiacast. Fizeram conexão e acesso ao HD externo, notebook, Data show, e celular por meio das entradas USB, HDMI, VGA, conexão óptica, Wi-fi, conexão Ethernet, Bluetooth, conexão de vídeo composto e conexão de áudio estéreo. Todos os professores participaram e apenas uma docente precisou repetir as ações para concluir a atividade.

em: <http://www.significados.com.br/smart-tv/>. Acesso em: 08 set. 2019. 
A partir das atividades com a Smart TV, foi tecida abordagem sobre a Internet das coisas ${ }^{4}$. Após a explanação, alguns professores exemplificaram a abordagem tratando sobre os objetos, equipamentos e máquinas que possuem que agregam as características referentes a internet das coisas, as quais destacaram a Smart TV, o carro, sistema de monitoramento residencial e o celular. Sobre este último meio tecnológico, foram desenvolvidas algumas atividades por meio do uso do celular ${ }^{5}$ na educação.

As atividades para uso do celular na educação foram desenvolvidas com intuito de apresentar aos professores algumas perspectivas para uso do aparelho em atividades com os alunos. A primeira atividade contemplada foi sobre a fotografia na aprendizagem, para desenvolver a prática da fotografia direcionada à aprendizagem dos alunos com olhar sobre a indisciplina e o foco na aprendizagem, por meio de aula expositiva sobre as técnicas da fotografia, indisciplina na escola, direcionamento para que os professores promovam debates com os alunos com foco na melhoria da educação escolar, desenvolvimento de práticas fotográficas em sala de aula e ambientes direcionados à cultura, esportes e lazer.

Após as explanações dos conteúdos com os docentes, fez-se o desafio para que estes profissionais aplicassem os conhecimentos desta atividade em ações educativas junto aos alunos, orientados, capacitados com algumas técnicas da fotografia, que pratiquem no cotidiano escolar e extraescolar com um olhar sobre a indisciplina e o foco na educação escolar. Os

\footnotetext{
${ }^{4}$ Segundo Singer (2012) a Internet das Coisas tem definição ampla sendo uma rede mundial de objetos conectados, que trocam informação entre si. É um conceito tecnológico em que todos os objetos da vida cotidiana estariam conectados à internet, agindo de modo inteligente e sensorial.

${ }^{5}$ Através da convergência tecnológica, que permitiu agregar sistemas de informática, comunicação e computação, o
}

professores se comprometeram em desenvolver a ação na escola e solicitar aos pais que auxiliassem seus filhos nas atividades extraclasse na composição das fotografias. Ficou acertado que a ação seria desenvolvida em um período de três semanas. A primeira semana voltada à parte teórica, na segunda semana à prática na escola e nos locais em que os alunos convivem fora da escola e na terceira semana reservada às apresentações e relatos das experiências e exposição das fotografias. Para esta atividade foram utilizados os celulares dos professores, uma máquina fotográfica, um computador e projetores de imagens.

Ainda utilizando o celular, foi sugerido a utilização de redes sociais e prontamente foi criado um grupo educomunicativo no WhatsApp, com intuito de estabelecer comunicação e apoio ao grupo de estudos que foi criado. A pretensão deste grupo de estudos é para troca de experiências, busca por melhoria na formação para utilização das tecnologias no processo de ensino-aprendizagem na instituição, colaboração nos estudos na formação no curso de capacitação online em informática na educação e futuramente, para preparação com a finalidade de pleitear acesso aos cursos de mestrado em educação disponíveis nesta capital.

Finalizada a capacitação presencial para a utilização de tecnologias no cotidiano da escola, os professores iniciaram as inscrições para participação no curso de capacitação $\mathrm{EaD}$ em práticas de informática na educação, fornecido por instituição parceira.

telefone celular se transformou em uma central multimídia computadorizada. Este recurso tecnológico vem sendo reconhecido também como objeto de aprendizagem devido a vários recursos disponíveis em um único aparelho que se apresenta como uma tecnologia multifuncional (FONSECA, 2013, p. 165). 
O curso de capacitação escolhido pelos participantes foi o de Práticas de Informática na Educação, por ser considerado pelos professores como complementar à capacitação presencial, ambas voltadas para utilização das tecnologias na educação. Em encontro presencial, no dia onze de agosto do corrente ano, com utilização de seis computadores da escola, nove notebooks e doze Smartphones dos próprios professores, os participantes da pesquisa efetivaram matrícula no curso de Práticas de Informática na Educação na plataforma da instituição de ensino superior parceira (Grupo Educacional Prominas e Faculdades Única - FUNIP https://cursos.faculdadeunica.com.br).

O passo seguinte foi a efetivação do primeiro acesso ao Portal do Aluno para ambientação e início da leitura do material didático disponibilizado em PDF. O curso teve duração de trinta dias, sendo quinze dias para leitura do módulo on-line intitulado "práticas de informática na educação" com atividades de leitura e chat, e quinze dias para responder a avaliação objetiva on-line. A carga horária do curso foi de quarenta e cinco horas (45).

A avaliação on-line foi organizada contendo dez questões objetivas de múltipla escolha, com questões de "a" a "e". Após a conclusão da avaliação, a nota foi disponibilizada na plataforma e na conclusão do período de trinta dias, o certificado foi disponibilizado para impressão em PDF e em papel por cada cursista.

O próximo passo entre as ações da pesquisaação, consistiu na aplicação dos conhecimentos adquiridos nos cursos presencial e on-line, no cotidiano da escola, com algumas turmas de primeiro ao quinto ano do Ensino Fundamental. Pois, apropriados dos conhecimentos teóricos e práticos adquiridos, os professores sentiram segurança em utilizar as tecnologias em seus fazeres diários na instituição.
Além dos cursos de capacitação oferecidos aos participantes da pesquisa-ação, foi concedida uma Pós-graduação Lato Senso em Gestão de Políticas Públicas para o pesquisador responsável pela pesquisa-ação, por ser servidor na instituição pesquisada e devido a iniciativa de parceria para a formação dos colegas na escola, tendo cursado integralmente no período de junho de dois mil e dezoito (2018) a agosto de dois mil e dezenove (2019). Os conteúdos contribuíram para atualização do pesquisador e para mediação do conhecimento junto aos membros da pesquisa.

As atividades com uso de tecnologias em suas respectivas salas de aula, foram desenvolvidas em dias alternados, perfazendo uma carga horária de duração de vinte (20) horas.

Entre as atividades desenvolvidas pelos professores com uso de tecnologias que integraram o fazer pedagógico na escola campo, foram utilizados os recursos tecnológicos dos próprios professores e os que a instituição dispunha.

Foi elaborado junto com os professores e alunos, uma lista de ações para serem desenvolvidas durante o segundo e terceiro bimestre do corrente ano, as quais foram elencadas as tecnologias que o professor e os alunos possuem em casa e as que estão disponíveis na escola. Assim foi estabelecido que as ações seriam:

- Dias para uso do celular na escola para registro fotográfico de ações educativas, como como ferramenta de pesquisa, office do google e comunicação e expressão (horário de pesquisa com wi-fi da escola aberto aos alunos);

- Pesquisa e construção de foguetes de canudinho, papel cartão e garrafas plásticas recicladas; 
- Registro fotográfico de momentos de aprendizagem, cultural, religioso, esportivo e de lazer;

- Projeto Inovação tecnológica: novo uso ou função para um produto (com ajuda dos pais);

- Grupo educomunicativo: grupo no WhatsApp para comunicação, troca de ideias, experiências, acompanhamento educacional por parte dos pais, professores e alunos.

Devido ao fato de a escola não dispor de recursos tecnológicos suficientes para que cada turma de alunos, pudessem desenvolver as atividades propostas, ambos utilizariam seus próprios recursos que dispunham em casa. Para não haver exclusão, devido um percentual das famílias não disporem de novas tecnologias (celular, tablete, notebook e outros), foi estabelecido pelos alunos que como a maioria dispõe destes recursos, compartilhariam com seus colegas.

Entre as cláusulas do Regimento interno da instituição, há a que trata da não permissão do uso de celulares em sala de aula. Após conversa e acordo com o grupo gestor, foi permitido que os alunos trouxessem o celular para uso específico nas aulas de tecnologias e em dias estabelecidos.

A utilização dos dispositivos móveis nas escolas é uma prática proibitiva devido aos usos inadequados, por dispersarem e distrair a atenção dos alunos. Esta alegação proferida nas instituições de ensino, tolhem a aprendizagem, principalmente em vista da perspectiva da adequação do professor quanto ao atendimento ao nativo digital. Diante das esporádicas vezes que o uso destas tecnologias é permitido, Moura (2017) enfatiza que:

A generalização dos dispositivos móveis em todas as camadas da sociedade particularmente nas gerações mais jovens, tem aberto caminho para novas abordagens no processo de ensino e aprendizagem. A aprendizagem ubíqua (aprender em qualquer lugar e a quaisquer professores em processos de interação, em diferentes espaços e momentos. Ajuda a fomentar as competências digitais dos alunos, em conjunto com uma melhora na aquisição dos conteúdos curriculares, e a suprimir problemáticas que vão surgindo ao longo do processo educativo (MOURA, 2017, p. 4).

Há que se rever as questões que dificultam a ação educativa. Por isso, o professor precisa agir e continuar buscando formação, principalmente quanto ao uso da internet, que em seu advento vem proporcionando diversas mudanças na sociedade e continua em constante transformação devido aos avanços tecnológicos, os fatores que os concebem, suas características e demais atributos que circundam sua composição diante do processo de comunicação. Esse meio facilitador desses processos trouxe velocidade de acesso à informação, interação e inúmeras outras possibilidades para inovação na pesquisa. Neste meio, "a informação rompe barreiras de tempo e espaço" (CASTELLS, 2003) difundindo sua função pós-massiva. Para desenvolver um papel fundamental na sociedade da informação $\mathrm{e}$ consequentemente na sociedade do conhecimento.

$\mathrm{O}$ primeiro questionamento indaga quais as estratégias de formação desenvolvidas na pesquisa, que o professor percebeu ser as que mais facilitaram o uso das TIC no seu cotidiano escolar.

Após o desenvolvimento das estratégias pelos professores, alguns obtiveram melhor atuação com a utilização da Internet na educação, tendo sido apontado por sete (7) dos professores. Seis (6) deles informaram que tiveram melhor atuação com uso do Datashow como recurso didático. Cinco (5) reconhecem que conseguiram melhores resultados com a utilização da Smart TV e o mesmo quantitativo informado pelos professores que atuaram buscando 
melhorias nos processos de ensinar e de aprender com manuseio do computador. Já os que obtiveram melhor atuação com uso do Paint na criação de atividades educativas foram quatro (4) professores.

Os vinte e sete (27) professores participantes informaram que durante o período de junho a outubro de dois mil e dezenove (2019), utilizaram todas as estratégias apresentadas nas capacitações da pesquisaação e se sentiram satisfeitos diante dos resultados obtidos, visto que anteriormente não conseguiam ou não utilizavam TIC no cotidiano da escola. Relataram ainda que irão dar continuidade na utilização destes recursos no fazer pedagógico diário e anseiam por ter oportunidade de usar melhores recursos disponíveis na escola e de utilizar novos recursos tais como: uma internet com capacidade para todos os professores utilizarem em sala de aula, computadores, Datashow, Smart TV e outros equipamentos disponíveis suficientes, bem equipados em bom estado de funcionamento para os professores desenvolverem seus planejamentos e um laboratório de informática com capacidade para, pelo menos, uma turma por vez.

Diante das necessidades e dificuldades por falta ou poucas tecnologias, os professores apresentaram suas expectativas e desejo que a escola adquira tecnologias para uso cotidiano e possam inovar nos processos de ensinar e aprender em suas ações diárias.

Após conclusão das capacitações e oficinas, os vinte e sete (27) professores demonstraram o nível de satisfação relacionado aos cursos, entre os quais, $80 \%$ se mostraram muito satisfeitos. Pois, segundo relato da professora "R", "cursos de capacitação são muito importantes para continuidade da nossa formação, devido ao fato de vivermos em uma era totalmente tecnológica e, se não nos capacitarmos estaremos muito distantes das necessidades de nosso público" (PROFESSORA “R”). Outros 20\% indicaram estar razoavelmente satisfeitos, embora sabendo que "o curso foi bastante relevante, mas precisamos dar continuidade nesta formação para aperfeiçoar a prática pedagógica e conseguirmos alcançar nossos alunos no novo e atual contexto social tecnológico e também em outras áreas como gestão de sala de aula, indisciplina e outras" (PROFESSORA "E"). Esta satisfação razoável se deu devido as formações serem voltadas apenas para a utilização de tecnologias no processo de ensino-aprendizagem na escola, demonstrando estarem necessitando de formação também em outras áreas.

Com referência ao curso de capacitação online de informática na educação, os professores pontuaram o nível de satisfação relacionada ao curso em que $75 \%$ deles disseram estar muito satisfeitos em ter participado e concluído o curso, e $25 \%$ informaram estar razoavelmente satisfeitos, pois devido suas dificuldades em utilizar hardware, software e ambientes virtuais, percebem que precisam de mais tempo de preparação para assimilação sobre o uso das novas tecnologias para que possam utilizá-las em suas práticas em sala de aula. "Esta capacitação trouxe informações avançadas e boas práticas quanto ao uso da informática na educação, mas deveria ter uma maior duração" (PROFESSORA “P”).

A continuidade na formação foi uma das necessidades mais comentadas pelos professores, pois sentem necessidade de melhorar suas práticas. Afirmaram que precisam de novos cursos e que sejam oferecidos pela escola ou pela Secretaria de Educação para que os docentes possam dar continuidade na sua formação, visto que sua melhoria refletirá na formação de seus alunos. Entre suas perspectivas, esperam que em futuro próximo, lhes seja ofertado novos cursos. Sobre esta questão, os professores pontuaram seus anseios e doze (12) deles discorreram que entre os cursos que almejam o mais emergente é sobre a indisciplina em sala de aula. Nove (9) professores informaram que carecem de capacitação sobre 
relações interpessoais. E seis relataram que há necessidade de capacitação em educação especial.

Outra demanda do grupo, incide sobre a pouca ocorrência e reduzida carga horária para os cursos de capacitação oferecidos pela escola ou SEMED, visto que em geral, têm oferecido cursos de capacitação apenas no início do ano e com carga horária que a própria SEMED não aceita como titularidade. Percebem ser adequada para a formação e valorização da carreira, cursos com no mínimo quarenta (40) horas aula.

Os professores anseiam por políticas públicas educacionais de continuidade de sua formação em serviço. Neste sentido, "A secretaria de educação e a gestão da escola, deveriam incentivar mais os seus profissionais para fazer cursos de formação continuada como capacitação, especialização, mestrado e doutorado. Percebo que não há uma motivação, tanto pela dificuldade financeira, quanto pela pouca valorização profissional. Nos falta políticas públicas" (PROFESSORA “K”)

A escola e os mantenedores da educação, precisam oferecer formação gratuita para seus professores, visto que são os principais interessados na qualidade da educação. É preciso que os gestores da educação busquem parcerias com as universidades para oferecer formação realmente continuada.

Faz-se necessária uma mudança de atitude, de postura e buscar na capacitação pela formação continuada, meios de conduzir a educação em que se está inserido a um patamar mais elevado do conhecimento. Mas, sem apoio, o professor corre o risco de viver adiando sua formação sem conseguir acesso a novos níveis do conhecimento. Os mantenedores da educação precisam criar políticas públicas mais efetivas, que impulsione a formação dos professores.

O processo de ensino-aprendizagem vem sendo favorecido pela utilização das novas tecnologias. Conforme Libâneo (2001) as mudanças tecnológicas recorrentes terão impacto cada vez maior nos processos educativos, no meio escolar e no cotidiano da sociedade. A inserção da tecnologia na educação vem criar meios para facilitar a comunicação e informação de forma paulatina, a partir dos diversos recursos didáticos pedagógicos facultados pelo uso do computador, da internet dentre outros meios que facilitaram o trabalho do educador.

A inserção da tecnologia na escola deve ser responsável pela segurança que os profissionais da educação possam sentir em buscar inovação na maneira de ensinar e de aprender. As novas tecnologias devem ser vistas como um recurso adicional, um instrumento complementar ao trabalho do professor em sala de aula. Desta forma, para que os profissionais da educação continuem tendo êxito e a educação perpetue o seu papel de formadora e transformadora da sociedade, faz-se necessário que os governantes direcionem mais investimentos, tecnologias, e principalmente na ampliação do potencial humano através de formação continuada gratuita e para todos os envolvidos, para que possam conduzir com mais propriedade às mudanças no processo de ensino-aprendizagem.

\section{CONCLUSÃO}

O desejo por mediar e compartilhar conhecimentos, oferecer possibilidades de formação, motivaram para o alcance do objetivo primordial da pesquisa que foi compreender quais as contribuições das estratégias educativas de uso das TIC para o aprimoramento dos docentes da escola campo de pesquisa. Pois a partir das pretensões de busca por melhorias no fazer pedagógico diário, estes profissionais almejavam efetivar ações de mobilização por toda a comunidade escolar.

Para atingir o objetivo proposto, foi necessário averiguar quais os desafios que a escola enfrenta 
quanto ao uso de TIC para o aprimoramento na formação da identidade docente, visto que há discrepâncias no processo de formação em serviço e dificuldades gritantes para uso destas tecnologias no ambiente escolar. Outro objetivo específico foi propor e desenvolver ações coletivas com uso de TIC no cotidiano escolar, durante o ano letivo, direcionadas ao aprimoramento da formação continuada dos professores, que executaram prontamente as ações propostas e interagiram com o grupo.

Durante a pesquisa, surgiram diversas dificuldades, a mais evidenciada foi o pouco tempo disponível para participar das capacitações devido os horários para planejamento e livre docência serem fragmentados e pouco coincidirem para que os docentes pudessem participar e interagir concomitantemente. O trabalho na instituição é intenso, mas há que se pensar em incluir na escola ações para formação continuada dos professores, para que além da experiencia cotidiana, possam inovar em seu fazer pedagógico.

A instituição pesquisada, enfrenta desafios, notadamente, no que se refere a recursos tecnológicos para uso individual e coletivo, incidindo em parte de suas carências, diante do quantitativo reduzido de equipamentos tecnológicos e a falta de capacitação relacionada ao saber utilizá-los. Essa necessidade é visível na maioria das escolas públicas, e não é diferente na escola pesquisada, que também dispõe de poucos recursos disponíveis, sendo insuficientes para suprir a demanda.

A instituição escolar aponta para a necessidade de apoio e de mudanças para que se possa repensar os modos, os processos, as estratégias e técnicas didáticas do fazer pedagógico com utilização de recursos tecnológicos. Para isso, precisa de apoio da gestão das políticas públicas da prefeitura desta capital, de apoio educacional da gestão escolar e da atuação da Secretaria de Educação com oferta de formação continuada adequada aos níveis para acesso às progressões horizontal e vertical exigidos para o plano de carreira pela própria instituição.

As TICs são recursos otimizadores das práticas educativas, consideradas pelos profissionais da instituição pesquisada como meios indispensáveis para auxiliar no processo de ensino-aprendizagem. Com estes recursos, os professores conseguem inovar em suas aulas, conquistando a atenção dos alunos, visto que as novas tecnologias são o passatempo mais frequente das crianças.

O processo educativo pelo qual foram conduzidas as ações desta pesquisa, evidenciou que as estratégias de formação de professores para uso de TIC na escola campo de pesquisa, ofereceu conhecimento técnico, pedagógico e metodologias diversificados para conduzir e mediar suas ações no intuito de desenvolver as ações educativas com criatividade, inovação, criticidade, mais contextualizados, eficientes, envolvente, desafiador e construtivo. Estes aspectos demonstram que os desafios da educação frente as novas tecnologias, diante dos poucos recursos disponíveis, não impedem que se possa efetivar ações educativas que deem conta de instigar os envolvidos à busca pelo conhecimento.

\section{AGRADECIMENTO}

Agradeço a todos os professores do curso de Mestrado em Gestão de Políticas Públicas - GESPOL, pela partilha e mediação do saber. A Universidade Federal do Tocantins, pela oportunidade para realização do curso. A todos, enfim, o meu sincero reconhecimento e agradecimentos

Todos os autores declararam não haver qualquer potencial conflito de interesses referente a este artigo.

\section{REFERÊNCIAS}


A ADELMAN, C. LEWIN, Kurt. And the origins of action research. Educ Act Res. 1993.

AVILA, Sarah Heidtmann. A construção da identidade docente no ensino superior e a sua preparação para atuar na educação a distância. Faculdade Anhanguera do Rio Grande. Instituto de Pesquisas Aplicadas e Desenvolvimento Educacional - IPADE. SARE. v.15 • n. $19 \cdot 2012 \cdot$ p. $141-149$. Disponível em: <http://pgsskroton.com.br/seer/index.php/educ/article /viewFile/1712/1637>. Acesso em 08 de mai. 2018.

BRANDÃO, C. R.; STECK, D. Pesquisa participante: a partilha do saber. São Paulo, Aparecida: Ideias e Letras, 2006.

BRASIL. Resolução 510, de 07 de abril de 2016. Brasília: Ministério da Saúde. Conselho Nacional de Saúde. 2016.

Resolução no 466/12. Brasília: Ministério da Saúde. Conselho Nacional de Saúde. 2012.

BRZEZINSKI, Iria. (Org.) Profissão professor: identidade e profissionalização docente. Brasília: Plano Editora, 2002.

CASADO, Frank Leonardo. SILUK, Julio Cezar Mairese. ZAMPIERI, Nilza Luiza Venturini. Universidade empreendedora e desenvolvimento regional sustentável: proposta de um modelo Entrepreneurial university and Regional sustainable development: Proposal of a model. Rev. Adm. UFSM, Santa Maria, v. 5, Edição Especial, p. 633-650, DEZ. 2012. Disponível em:

<https://periodicos.ufsm.br/reaufsm/article/download/ 7755/pdf $\rangle$. Acesso em 09 mar. 2018.

CASTELLS, M. A galáxia da internet: reflexões sobre a internet, os negócios e a sociedade. Rio de Janeiro, Jorge Zahar Ed., 2003.

CASTRO Darlene Teixeira. Sociedade da informação, inovação, tecnologia e cibercultura. In. PÔRTO Jr, Gilson.; CASTRO, Darlene Teixeira; MELO, Gabriela Pereira; BACELAR, Alessandra (Orgs.). Comunicação, ensino e tecnologia: experiências e discussões pertinentes à formação do profissional. Porto Alegre, RS: Editora Fi, 2017.

FALS BORDA, O. La ciencia y el pueblo. Bogotá: Punta de Lanza, 1980.

FERREIRA, Naura Syria Carapeto. Gestão democrática da educação: atuais tendências, novos desafios. São Paulo: Cortez, 2008.
FLICK, Uwe. Desenho da pesquisa qualitativa. Coleção Pesquisa Qualitativa (Coordenação de Uwe Flick). Porto Alegre: Bookman, Artmed, 2009a.

Qualidade na pesquisa qualitativa. Coleção Pesquisa Qualitativa (Coordenação de Uwe Flick). Porto Alegre: Bookman, Artmed, 2009b.

FONSECA, Ana Graciela M. F. da. Aprendizagem, mobilidade e convergência: Mobile Learning com Celulares e Smartphones. Mídia e Cotidiano - UFF. Número 2. 163-181 Junho 2013. Disponível em: <periodicos.uff.br>. Acesso em: 05 de ago. 2019.

GENTILI, Pablo. Escola S. A.: quem ganha e quem perde no mercado educacional do neoliberalismo. Brasília: CNTE, 1996, p. 9 - 49.

LAPA, Andrea; PRETTO, Nelson De Luca. Inovar com os Hackers na Educação. In: DIAS, Paulo; MOREIRA, Darlinda; QUINTAS-MENDES, António (Org). Inovar para a qualidade na educação digital. Covilhã: Universidade Aberta, 2019, p. 104-116. Coleção Educação a Distância e eLearning. $\mathrm{N}^{\circ} 6$. 2019. Disponível em: <www.uab.pt> Acesso em: 08 de nov. de 2019.

LE BOTERF, G. Pesquisa participante: propostas e reflexões metodológicas. In: BRANDÃO, C. R. (Org.). Repensando a pesquisa participante. São Paulo: Brasiliense, 1984.

LEMOS, André. (Ed.). Cidade digital: portais, inclusão e redes no Brasil. Salvador: Edufba, 2007.

LEWIN, K. Action research and minority problems. J Soc Issues.1946.

LIBÂNEO, José Carlos. Organização e gestão da escola: teoria e prática. Goiânia: Editora Alternativa. 2001.

MOURA, Adelina. Metodologias de aprendizagem que desafiam os alunos, mediadas por tecnologias digitais. Palmas: Revista Observatório, v. 3, n. 4, p. 256- 278, jul-set. 2017. Disponível em: $<$ https://sistemas.uft.edu.br/periodicos/index.php/obs ervatorio/article/view/3466/9784> Acesso em 24 fev. 2018.

PRETTO, Nelson De Luca. Educações, culturas e hackers: escritos e reflexões. EDUFBA: Salvador, 2017.

PRETTO, Nelson De Luca; SOUZA, Joseilda Sampaio de; ROCHA, Telma Brito. Tabuleiro digital: uma experiência de inclusão digital em ambiente educacional. In: BONILLA, Maria Helena 
Silveira; PRETTO, Nelson De Luca (org). Inclusão digital: polêmica contemporânea. Salvador: EDUFBA, 2011.

SINGER, Talyta. Tudo conectado: conceitos e representações da internet das coisas. Simpósio em Tecnologias Digitais e Sociabilidade - Práticas Interacionais em Rede. 2012.

TARDIF, Maurice. Saberes docentes e formação profissional. Petrópolis, RJ: Vozes, 2002.
TARDIF, Maurice. LESSARD, Claude. O trabalho docente: elementos para uma teoria da docência como profissão de interações humanas. 6. Ed. Rio de Janeiro: Vozes, 2011.

THIOLLENT, M. Metodologia da pesquisa-ação. $18^{a}$ ed. São Paulo: Cortez, 2011.

Pesquisa-Ação nas Organizações. São Paulo: Atlas, 1997. 